\title{
7. 肥満児およひ㾖身者の身体運動時のエネルギー代謝について
}

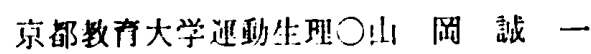

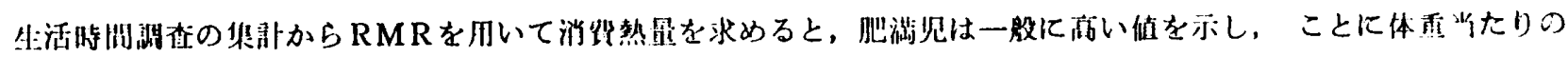

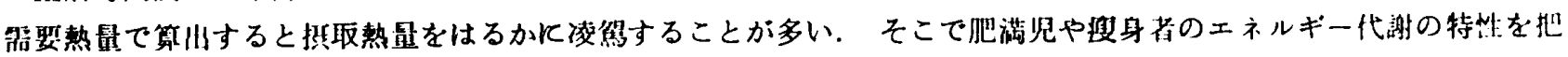

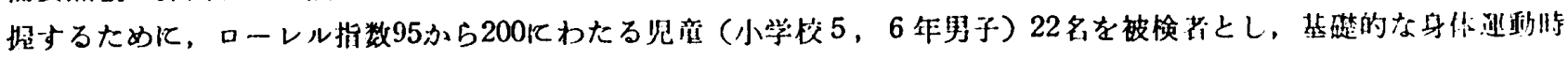

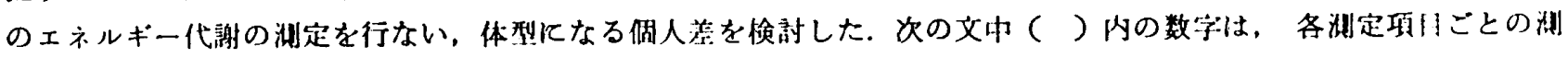

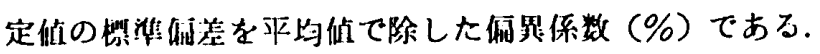

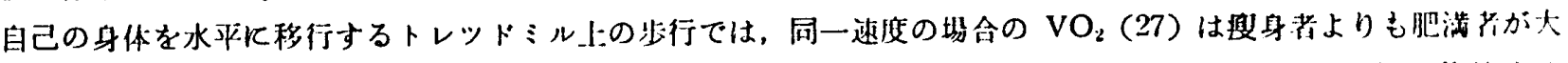

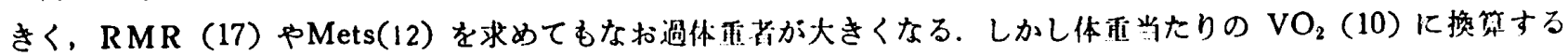

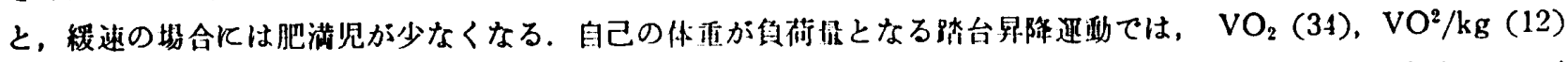

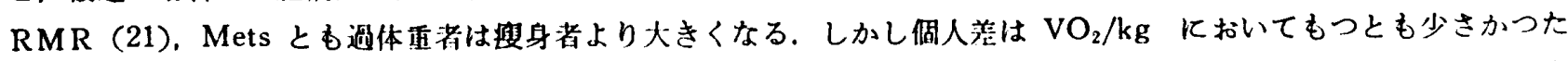

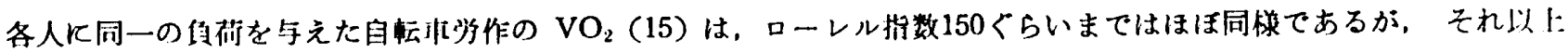

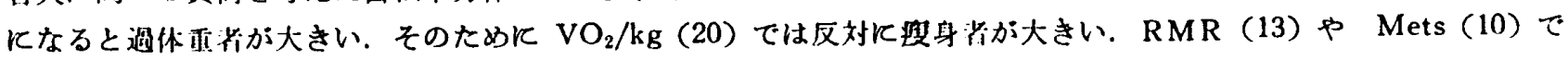

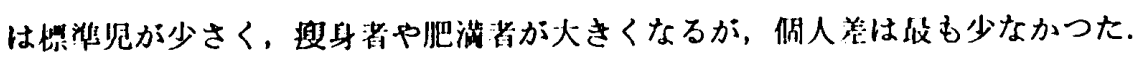

\section{8. 中高年者の体力（運動経適田）について一心拍数からみた一}

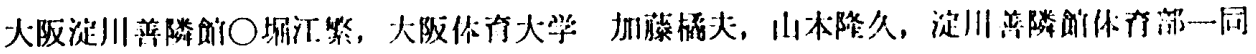

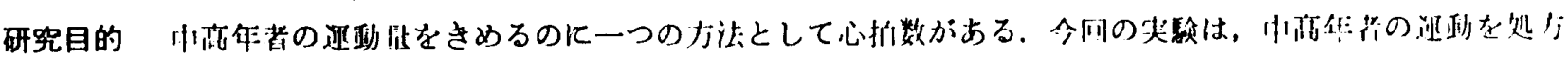

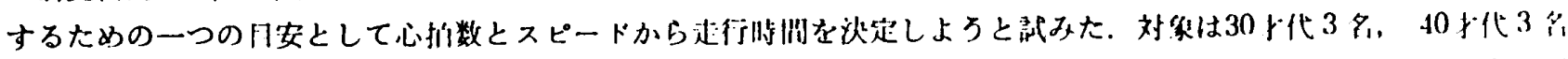

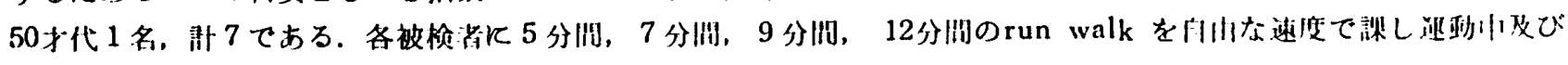

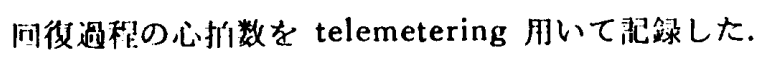

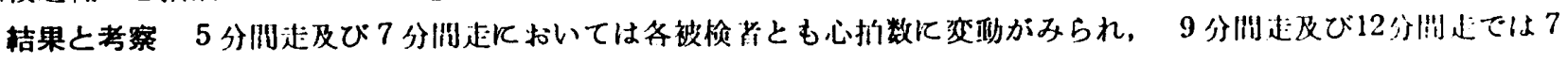
分䦌位でほほ steady state K入つている。

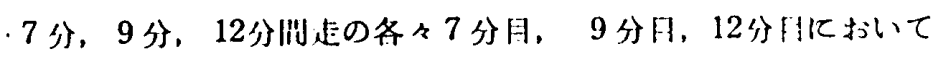

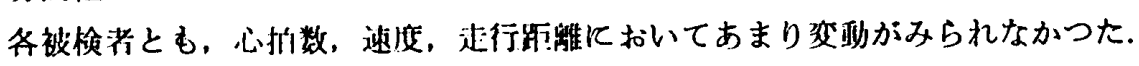

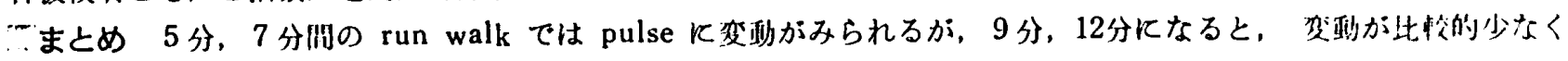

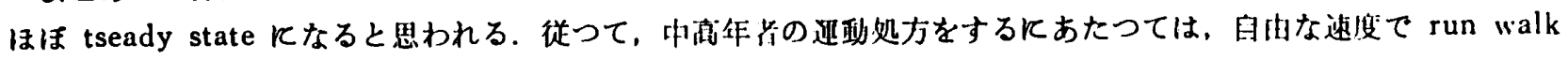

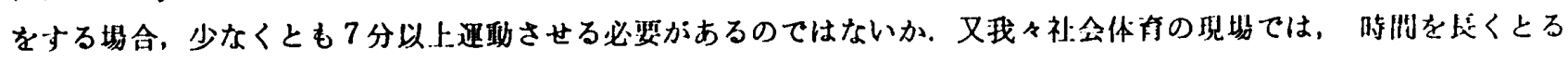

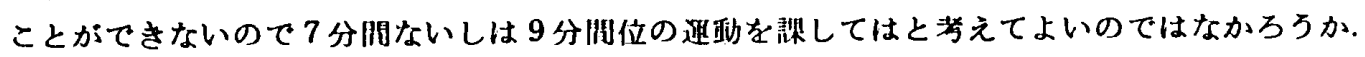

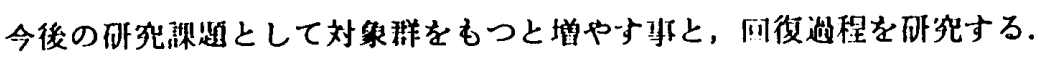

\section{9. 筋力発達の性差}

東京学忶大学○小野三䀦，波多野義郎，丹羽 昇

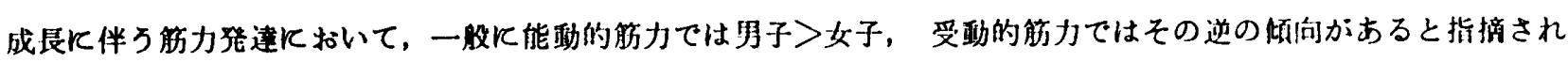

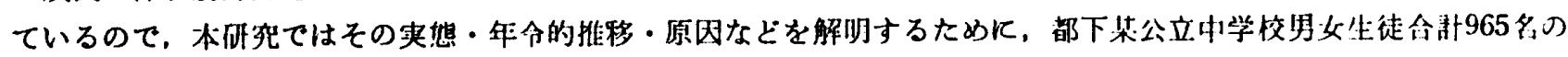

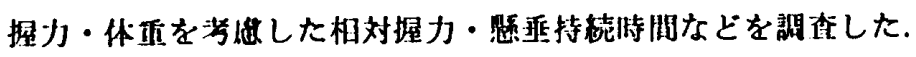

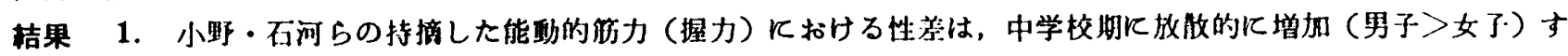

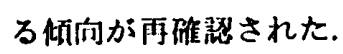

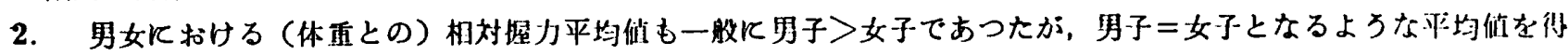

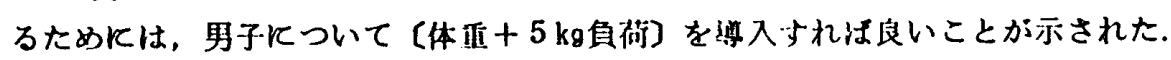

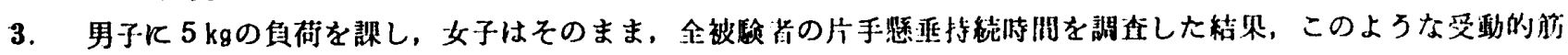

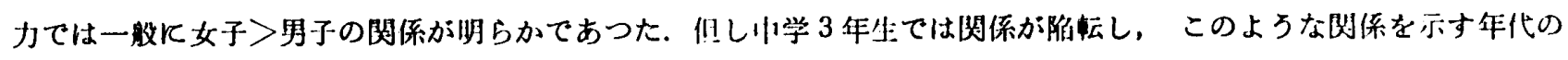
限界を示惨している。

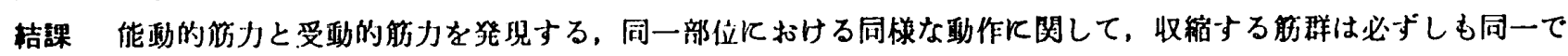

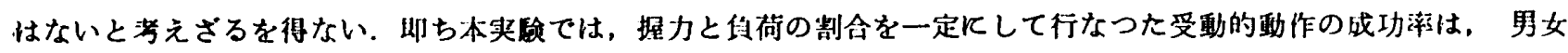

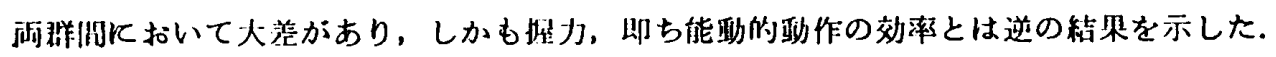

